\title{
Editorial
}

\section{Corrosion of Nonferrous Metals and Their Alloys}

\author{
Alicia E. Ares $\mathbb{D}^{1}{ }^{1}$ Raúl B. Rebak, ${ }^{2}$ María V. Biezma $\mathbb{D}^{3},{ }^{3}$ and Claudia M. Méndez $\mathbb{D}^{4}$ \\ ${ }^{1}$ Instituto de Materiales de Misiones (IMAM), Consejo Nacional de Investigaciones Científicas y Técnicas (CONICET), \\ Universidad Nacional de Misiones (UNaM), Posadas, Misiones, Argentina \\ ${ }^{2}$ GE Global Research, Schenectady, NY, USA \\ ${ }^{3}$ Universidad de Cantabria, Santander, Spain \\ ${ }^{4}$ Universidad Nacional de Misiones, Posadas, Misiones, Argentina
}

Correspondence should be addressed to Alicia E. Ares; aares@fceqyn.unam.edu.ar

Received 13 March 2018; Accepted 14 March 2018; Published 31 May 2018

Copyright ( 2018 Alicia E. Ares et al. This is an open access article distributed under the Creative Commons Attribution License, which permits unrestricted use, distribution, and reproduction in any medium, provided the original work is properly cited.

Corrosion is the result of the interaction of a material (metal) with its environment.

The corrosion process depends on the properties of both metal (and alloy) and surrounding environment. Usually, the more important factors causing corrosion are concentration of aggressive species (e.g., chloride), acidity ( $\mathrm{pH})$, fluid velocity, temperature, and potential (oxidizing power).

Steel and other ferrous alloys are consumed in exceedingly large quantities because they have such a wide range of mechanical properties, may be fabricated with relative ease, and are economical to produce. However, steels have some distinct limitations, chiefly a relatively high density, a comparatively low electrical conductivity, and an inherent susceptibility to corrosion in some common environments.

Thus, for many applications, it is advantageous or even necessary to use other alloys that have more suitable property combinations. Alloy systems are classified either according to the base metal or according to some specific characteristic that a group of alloys shares. Authors were invited to submit original research articles and reviews for this special issue that included all aspects of the corrosion process of the following metal and alloy systems: aluminum, copper, magnesium, and titanium alloys; the refractory metals; the superalloys; the noble metals; and miscellaneous alloys, including those that have nickel, lead, tin, zirconium, and zinc as base metals.

The papers published in this special issue are as follows:

(i) "Synthesis of Copper Oxide Aided by Selective Corrosion in Cu Foils," by Roberto Baca Arroyo.
The authors present the synthesis of $\mathrm{Cu}$ oxide films aided by selective corrosion of $\mathrm{Cu}$ foils with a subsequent heating process in air atmosphere at low temperatures.

(ii) "Effects of Alloying Elements (Cr, Mn) on Corrosion Properties of the High-Strength Steel in $3.5 \% \mathrm{NaCl}$ Solution," by BomiKim, Soojin Kim, and Heesan $\mathrm{Kim}$. The authors study the effects of manganese and chromium on corrosion resistance of high manganese steels by examining the rust properties with X-ray diffraction (XRD), Raman spectroscopy, energy dispersive spectroscopy (EDS), and electron energy loss spectroscopy (EELS) adjunct to transmission electron microscopy (TEM).

(iii) "Transition of Dislocation Structures in Severe Plastic Deformation and Its Effect on Dissolution in Dislocation Etchant," by Muhammad Rifai, EbadBagherpour, Genki Yamamoto, Motohiro Yuasa, and Hiroyuki Miyamoto. The authors analyse the effect of SSE passes on the dissolution employing the modified Livingston etchant, which is very sensitive to dislocations.

(iv) "Effect of Partial Cladding Pattern of Aluminum 7075 T651 on Corrosion and Mechanical Properties," by Rendell, Hsiao, and Shirokoff. The authors estimate the clad spot to determine dimensions for a two-dimensional aluminum alloy array.

(v) "Effect of Molybdenum on the Corrosion Behavior of High-Entropy Alloys (HEAs) $\mathrm{CoCrFeNi} \mathrm{Ci}_{2}$ and 
CoCrFeNi ${ }_{2} \mathrm{Mo}_{0.25}$ under Sodium Chloride Aqueous Conditions," by Alvaro Rodriguez, Joseph Tylczak, Michael Gao, Paul D. Jablonski, Martin Detrois, Margaret Ziomek-Moroz, and Jeffrey Hawk. The authors investigate the corrosion behavior of highentropy alloys (HEAs) $\mathrm{CoCrFeNi} \mathrm{N}_{2}$ and $\mathrm{CoCrFe}-$ $\mathrm{Ni}_{2} \mathrm{Mo}_{0.25}$ in 3.5 wt. percent sodium chloride $(\mathrm{NaCl})$ at $25^{\circ} \mathrm{C}$ by electrochemical methods.

Alicia E. Ares

Raúl B. Rebak María V. Biezma

Claudia M. Méndez 


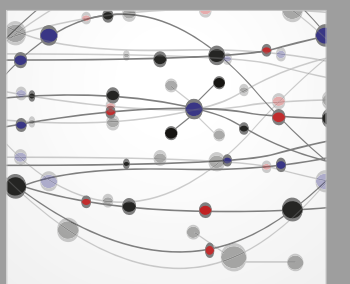

The Scientific World Journal
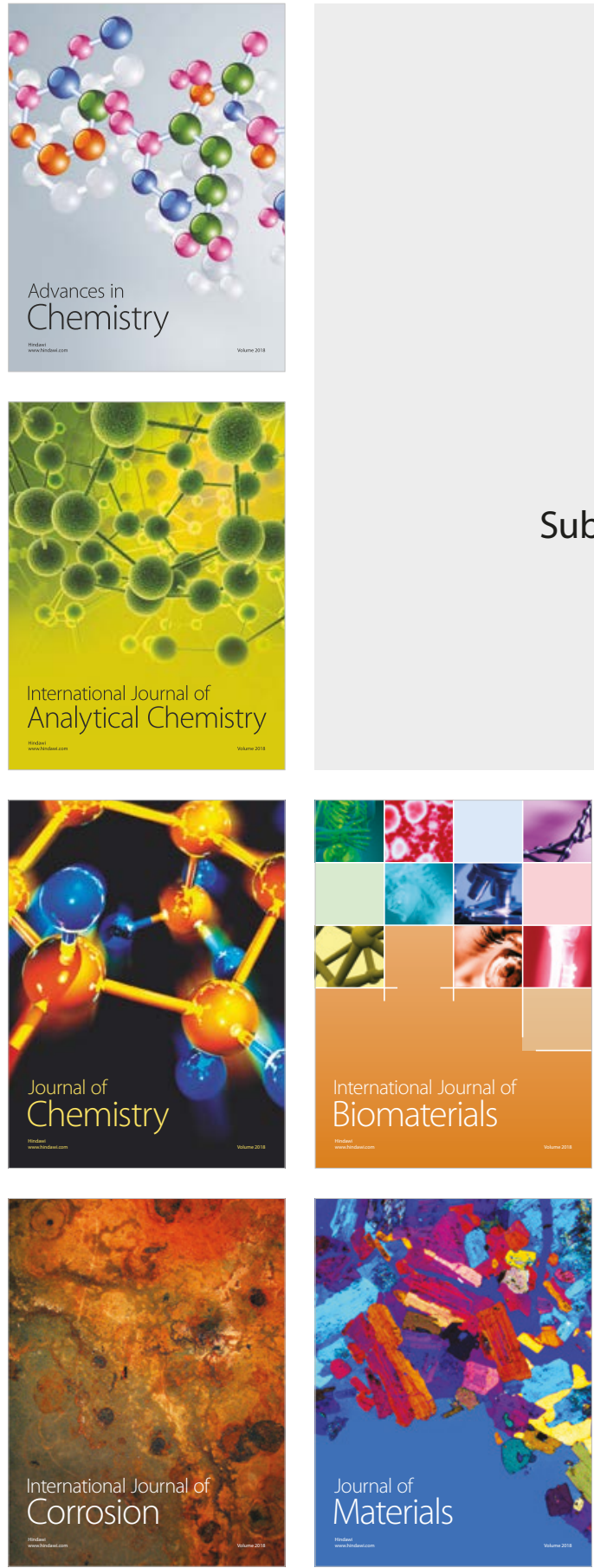

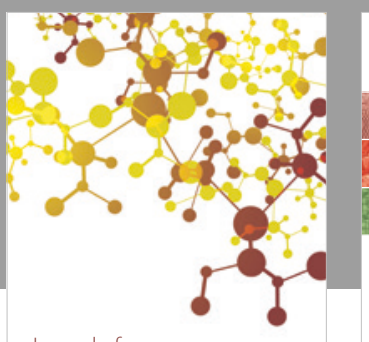

Journal of

Applied Chemistry
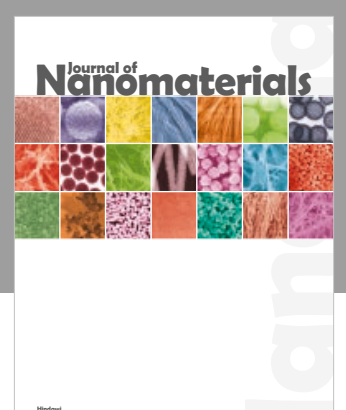

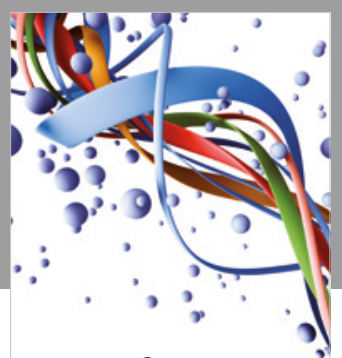

Scientifica

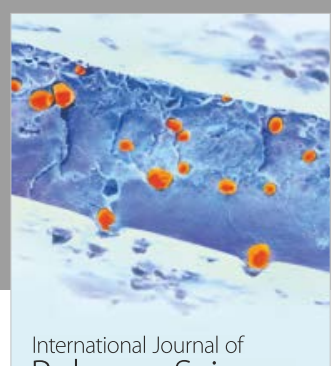

Polymer Science

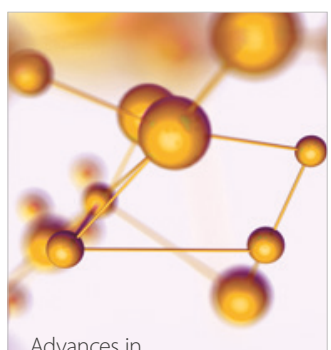

Physical Chemistry
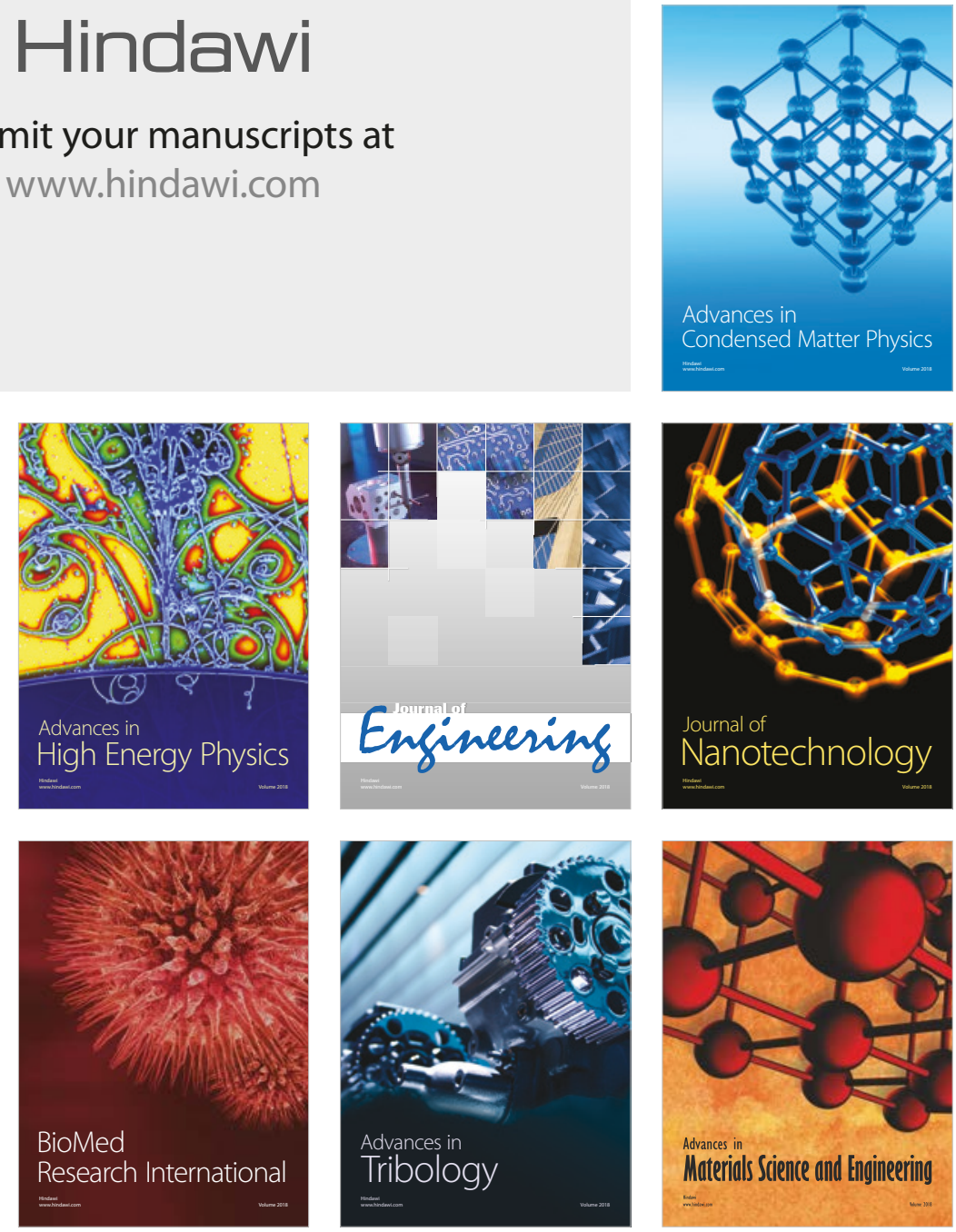